\title{
Lung cancer and tuberculosis: A case report on a patient with concurrent comorbidities in a hospital of high complexity in Fortaleza - CE-BR
}

\author{
Jose Aurillo Rocha, Filadelfia Passos Rodrigues Martins, Rosineli Leopoldino De Oliveira, \\ Paulo Brito De Castro Figueira, Jose Dumas Ferreira Gomes, David Luniere Goncalves
}

Clinical Oncology, Messejana Hospital- Dr. Carlos Alberto Studart Gomes- Avenida Frei Cirilo, 3480 - Messejana - CEP - 60.846-190

Fortaleza/Ce/ Brazil

\section{Email address:}

jaurillor@hotmail.com (J. A. Rocha)

\section{To cite this article:}

Jose Aurillo Rocha, Filadelfia Passos Rodrigues Martins, Rosineli Leopoldino De Oliveira, Paulo Brito De Castro Figueira, Jose Dumas Ferreira Gomes, David Luniere Goncalves. Lung Cancer and Tuberculosis: A Case Report on a Patient with Concurrent Comorbidities in a Hospital of High Complexity in Fortaleza - CE-BR. Cancer Research Journal. Vol. 2, No. 6, 2014, pp. 102-103. doi: $10.11648 /$ j.crj.20140206.11

\begin{abstract}
Case report: Lung Cancer (LC) is associated with smoking. Wonders attention in people with lung cancer who also have increased risk of having pulmonary tuberculosis (PT). The chances of getting lung cancer among pulmonary tuberculosis increases compared to LC alone. Simultaneously or not can change the prognosis and survival of these patients. The objective of this case report is to highlight the characteristics and possibilities of patients with PT and LC, with simultaneous or sequential presentation outpatient tertiary Hospital / high complexity. Tuberculosis screening should be recommended prior to initiating immunosuppressive treatment of LC.
\end{abstract}

Keywords: Lung Cancer, Tuberculosis, Concorrent Comorbities

\section{Case Report}

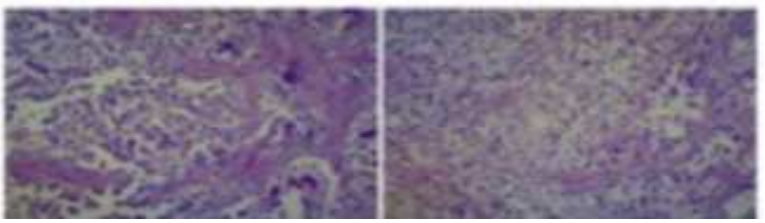

Fig 1. TC contrasted of the chest with left extrapulmonary mass and soft tissue edema with lymphadenopathy mediatinal left.

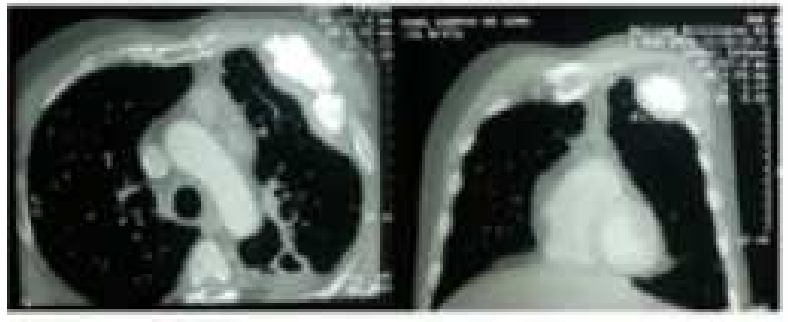

Fig 2. Lymph node biopsy:moderately differentiated adenocarcinoma
Patient, 57 years. old, male, resident in Fortaleza. Admitted complaining of tiredness in Messejana Hospital on 15/01/2014, with diagnosis of PT since December-2012, came into noncompliance COXCIP-4 (Isoniazid-75 mg; Ethambutol dihydrochloride-275 mg; Pyrazinamide-400 mg;Rifampicin-150 mg).In his internment-presented with dyspnea (Oxigen saturation: 78\%), associated with fever, malaise and appetite loss. Comorbidities: Hypertension. Heavy drinker and smoker great. On january.18.2014 confirms a Multi-resistant PT. On january 23.2014 it was noted the bulging clinical examination in the left infraclavicular region was requested chest tomography, which showed the presence of calcified to the 1 st rib associated with diffuse mediastinal lymph node mass level. Then done lymph node biopsy. Result of Pathology metastatic poorly differentiated carcinoma. Immunohistochemistry of cervical lymph node biopsy: adenocarcinoma metastasis. CEA: $25.0 \mathrm{ng} / \mathrm{ml}$. CA19-9: $12.7 \mathrm{U} / \mathrm{ml}$. Remained hospitalized due to fever infectious complications associated with worsening of dyspnea and blood count (leukocytosis), and then used antibiotic therapy, and show signs of worsening disease evolving to abdominal 
pain and respiratory distress. Exams: EDA: enanthematous mild gastritis of the antrum. Colonoscopy: inconclusive. Other tests: Research BAAR: 15/01/2014 (at admission): positive. BAAR: 06/04/2014 and 05/06/2014: Positive.

\section{Discussion}

In this report, as in most patients with PT and LC, the association with smoking and tuberculosis was diagnosed either before or simultaneously with the diagnosis of cancer. Adenocarcinoma is the most common histologic type in this situation $(2,3,10,11)$. Increased LC in patients with PT occurrence may be related to immunosuppression $(1,9)$; On the other hand, the immunodepression caused by cancer or chemotherapy might increase the reactivation of TB in patients with solid tumors (4.9). When PT is diagnosed simultaneously with the diagnosis of neoplasia appears to be no change in the prognosis $(7,10)$. One study showed that the association between PT and LC varies in sociodemographic groups (10). It is important to know the characteristics of these cases in our population, high prevalence of both diseases. Although the additive effects of tobacco carcinogen, the relationship between pulmonary PT and LC persists even after controlling for smoking, with up to 2.5-fold increased risk of cancer among patients with TB. The initial symptoms of lung cancer can be confused with symptoms of PT, and the importance of these cases lies in the fact that patients diagnosed with PT must be accompanied with a critical vision and avoid the most delay appropriate treatment $(1,6,8)$. Identify patients with active PT, quantify the prevalence of these and respiratory symptoms, determine the sensitivity of M. tuberculosis isolated and identified strains of $M$. tuberculosis cause PT among patients undergoing cancer treatment should always be in mind. Considering the expected incidence of PT and LC in the general population, which is growing steadily and becoming resistant to common treatment, the incidence of patients with smear-positive pulmonary PT in patients with LC may also be changing and worsening morbidity and survival $(5,8,12)$.

\section{Conclusion}

As a result of the high prevalence of PT and LC in our counrtry, the policy in Fortaleza-Brazil for patients with positive acid-fast smear results and typical TB imaging is to start treat- ment immediately; not different of LC; affecting populations at risk. This article is to emphasize a addition to the literature on the management of both diseases in countries with a high burden of tuberculosis where tuberculosis screening should be recommended prior to initiating immunosuppressive treatment of LC.

\section{References}

[1] Arslam O, Gurman G, Dilek I et al. Incidence of tuberculosis after bone marrow transplantation in a single center from Turkey. Haemathologie, 1998, 29(1):59-62.

[2] Dye C, Scheele S, Dolin P, Pathania V, Raviglione MC. Global burden of tuberculosis: estimated incicence, prevalence and mortality by country. JAMA 2000, 282(7): 678-686.

[3] Ip MS, Yuen KY, Woo, PC et al. Risk Factors for pulmonary tuberculosis in bone marrow transplant recipients. Am J Respir Crit Care Med, 1998, 158(4):1173-1177.

[4] Brasil Ministério da Saúde. Tuberculose: Guia de Vigilância Epidemiológica. 2002. FUNASA, Brasília-DF, 100p. Libshitz HI, Pannu HK, Elting LS, Cooksley CD. Tuberculosis in cancer patients: an update. J Thorac Imaging 1997, Jan;12(1):41-6.

[5] Melo FAF, Afiune JB. Tuberculose, uma doença ocupacional: infecção, adoecimento, proteção dos profissionais em Serviços de atenção à tuberculose. Bol Pneum Sanit, 1995, 3(1):56-68.

[6] Yuen KY, Woo PC. Tuberculosis in blood and marrow transplant recipients. Hematol Oncol. 2002 Jun;20(2):51-62.

[7] Libshitz HI, Pannu HK, Elting LS, Cooksley CD Tuberculosis in cancer patients: an update. J Thorac Imaging. 1997 Jan;12(1):41-6.

[8] Tamura A, Hebisawa A, Tanaka G, Tatsuta H, Tsuboi T, Nagai H, Hayashi K, Sagara Y, Kawabe Y, Akagawa S, Nagayama N, Machida K, Kurashima A, Sato K, Fukushima K, Yotsumoto $\mathrm{H}$, Mori M. Active pulmonary tuberculosis in patients with lung cancer. Kekkaku. 1999 Nov;74(11):797-802.

[9] Gómez-Marin JE+, León Franco CIL, Guerrero MI, Rigouts L, Portaels F. S6110 Fingerprinting of Sensitive and Resistant Strains (1991-1992) of Mycobacterium tuberculosis in Colombia. Mem Inst Oswaldo Cruz 2002, 97(7): 1005-1008.

[10] Kolk AHJ, Kox LFF, Van Leeuwen J, et al. Clinical utility of the polymerase chain reaction in the diagnosis of extrapulmonary tuberculosis. Eur Respir J 1998; 11: 12221226.

[11] Arthritis Care \& Research; Vol. 64, No. 11, November 2012, pp 1783-1786 (C) 2012, American College of Rheumatology.

[12] Increased prevalence of primary drug-resistant pulmonary tuberculosis in immunocompromised patients- Respirology (2011) 16, 308-313 doi: 10.1111/j.1440-1843.2010.01902.x 